\title{
NEOSTIGMINE REVERSAL OF D-TUBOCURARINE AND PANCURONIUM BROMIDE COMBINATIONS IN MAN
}

\author{
DAVID Z.N. FRANKEL
}

\begin{abstract}
This study measured the neostigmine reversal of a non-depolarizing block in 17 patients, each given d-tubocurarine and pancuronium bromide in an alternating sequence. Reversal times were similar to those previously reported for pancuronium bromide alone. It is concluded that the anaesthetist may alternate between d-tubocurarine and pancuronium bromide without fear of difficulty with neostigmine reversal.
\end{abstract}

Key Words: NeURomuscular Relaxants, mixtures, d-tubocurarine-pancutonium; antagonists, NeUromuscular Relaxants, Neostigmine.

The ANAESTHETIST's ChOICE of non-depolarizing muscle relaxant is determined by many contributing factors including the type and duration of procedure, the patient's cardiovascular, respiratory and renal status, and previous anaesthetic experience. However, the ideal choice of muscle relaxant might change in the course of the anaesthetic and the anaesthetist may want to change from one non-depolarizing relaxant to another.

While adequate relaxation can be obtained with non-depolarizing relaxant mixtures, the anaesthetist is concerned with the ease of reversing such relaxant combinations. The purpose of this study was to examine the neostigmine reversal of patients given d-tubocurarine (dTc) and pancuronium bromide ( $\mathrm{PCB}$ ) in an alternating sequence.

\section{METHODS}

Seventeen patients, 12 female and five male, were studied. All were undergoing elective procedures of more than one hour duration requiring tracheal intubation and muscle relaxation. The preponderance of female patients was due to gynaecological patients being included in the study. All patients were A.S.A. class I or II, had no history of renal, hepatic or neuromuscular disease, and had no contraindications to the

David Z.N. Frankel, M.D., M.Sc., F.R.C.S.(C), Department of Anaesthesia, Shaare Zedek Medical Centre, P.O.B. 293, Jerusalem, Israel. 91002

This work was done in the Department of Anaesthesia at the Toronto General Hospital, Toronto, Canada.

Can. Anaesth. Soc. J., vol. 29, no. 4, July 1982 use of either dTc or PCB. All patients were premedicated with intramuscular meperidine 50 $\mathrm{mg}$ and promethazine $25 \mathrm{mg}$ approximately one hour before operation.

For induction, patients were given a sleep dose of sodium thiopentone and d-tubocurarine or pancuronium, as described below, for tracheal intubation and muscle relaxation during the operation. Anaesthesia was maintained with 67 per cent nitrous oxide in oxygen and intravenous meperidine as required. Ventilation was controlled through a circle system with a tidal volume of $10 \mathrm{ml} \cdot \mathrm{kg}^{-1}$ at a frequency of 12 breaths per minute. Fresh gas flows were set to maintain $\mathrm{PaCO}_{2}$ between $4.7 \mathrm{kPa}(35 \mathrm{~mm} \mathrm{Hg})$ and $5.3 \mathrm{kPa}$ (40 $\mathrm{mm} \mathrm{Hg}$ ) as described previously. ${ }^{1}$ An oesophageal temperature probe was placed after tracheal intubation. Train-of-four stimulation ${ }^{2}$ of the facial or ulnar nerve (constant for any one patient) was done with surface gelled electrodes and supramaximal square wave pulses of 0.2 msec in duration at $2 \mathrm{~Hz}$ for 2 seconds.

Muscle relaxants were administered in a manner imitating the most extreme clinical situation: every time more relaxant was required, the choice of muscle relaxant changed. Patients were divided randomly into two groups. In Group $A$ the trachea was intubated three minutes after administration of d-tubocurarine $0.4 \mathrm{mg} \cdot \mathrm{kg}^{-1}$ followed by pancuronium for the first incremental dose, d-tubocurarine for the second and so on, alternating between the two. Group B the trachea was intubated three minutes after administration of pancuronium 0.08 $\mathrm{mg} \cdot \mathrm{kg}^{-1}$, followed by d-tubocurarine for the 395 
first incremental dose, pancuronium for the second and so on, alternating between the two. Ten minutes after the intubating dose, if three twitches of the train-of-four were still visible (corresponding to greater than 20 per cent of control height of a single twitch ${ }^{2}$ ) the first incremental dose of the altemative relaxant was given in an amount ensuring that two or fewer twitches of the train-of-four were visible. After all four twitches had returned, incremental doses were administered in an amount sufficient to produce two or fewer twitches, if the operation was to continue for more than one half hour. At the end of the operation the muscle relaxants were reversed with neostigmine $0.04 \mathrm{mg} \cdot \mathrm{kg}^{-1}$ and atropine $0.02 \mathrm{mg} \cdot \mathrm{kg}^{-1}$ intravenously. "Full recovery" was defined as visually sustained tetanus for five seconds in response to a supramaximal stimulus at $50 \mathrm{~Hz}$. The time from neostigmine administration to full recovery was noted. One hour after admission to the recovery room, patients were tested for the ability to maintain a head lift for five seconds.

\section{RESULTS}

Group A consisted of eight patients of average age $40 \pm 13$ ( \pm 1 S.D.) years and average weight $67 \pm 8 \mathrm{~g}$. Group B consisted of nine patients of average age $39 \pm 14$ years and average weight $65 \pm 9 \mathrm{~g}$. After the initial intubating dose of muscle relaxant, all patients required at least one additional dose. There was no significant difference between the two groups in either the duration of anaesthesia, (Group A $109 \pm 34$ minutes and Group B $111 \pm 41$ minutes) or the number of supplemental relaxant doses required after intubation (Group A $1.9 \pm 0.8$ and Group B $2.2 \pm 1.3$ ). Adequate surgical relaxation was obtained in all patients. All patients maintained an oesophageal temperature of $35.5^{\circ}$ to $37.5^{\circ} \mathrm{C}$, during the study.

The time for reversal to sustained tetanus at 50 $\mathrm{Hz}$, is illustrated in Figure 1. When three or more twitches of the train-of-four were present, corresponding to greater than 20 per cent of control height the time to full recovery following neostigmine was 2.5 to 17 minutes. When two or fewer twitches of the train-of-four were visible corresponding to less than 20 per cent of control height the time for full reovery was 6.5 to 25.5 minutes. One hour after admission to the recovery room, all patients were able to sustain a head lift for five seconds.

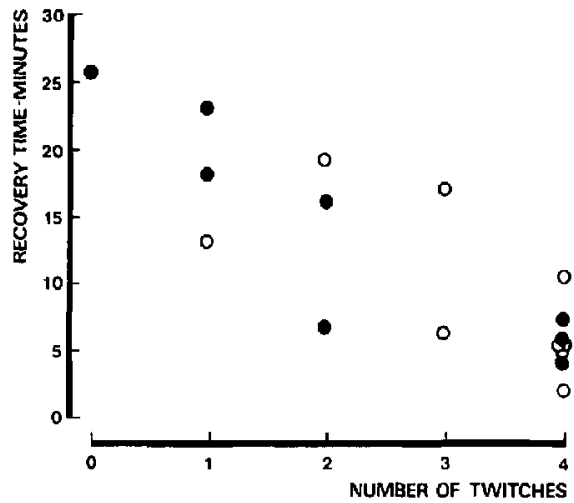

FIGURE 1 Recovery time to sustained tetanus at 50 $\mathrm{Hz}$. vs. number of twitches of the train-of-four immediately preceding reversal. Group A (dTc, PCB dTc, etc.) - Group B (PCB, dTc, PCB, etc.) - O.

\section{Discussion}

The results of this study are similar to the results of $\mathrm{Katz}^{3}$ who measured the reversal times for pancuronium alone. Katz found that if the twitch height was greater than 20 per cent of control, reversal time was 3 to 14 minutes (compared to 2.5 to 17 minutes in the present study). If the twitch height was less than 20 per cent of control, Katz found that the reversal time was 8 to 29 minutes (compared to 6.5 to 25.5 minutes in the present study). Thus, the reversal times following alternating doses of d-tubocurarine and pancuronium are similar to those for pancuronium alone.

In the present study, pancuronium was assumed to be five times as potent as d-tubocurarine for the intubating dose. This corresponds closely to the 5.5:1 ratio described by Krieg, Crul and Booij, ${ }^{5}$ but somewhat less than the 6:1 ratio reported by Savarese, Ali and Antonio. ${ }^{6}$ In the present study, however, there was no significant difference between the number of incremental doses required by Group $A(1.9 \pm 0.8)$ or Group B (2.2 \pm 1.3$)$.

The train-of-four stimulation was given at either the facial or ulnar nerve through surface gelled electrodes. Stiffel, et $a .^{4}$ have shown that, compared with standard ulnar needle electrodes, ulnar surface electrodes tend to overestimate and periorbital surface electrodes to underestimate the neuromuscular block. This was equally true for train-of-four measurements and recovery times from succinylcholine. In the 
present study, therefore, the site of stimulation of both train-of-four and sustained tetanus was kept constant for any one patient.

Lebowitz, Ramsey, and Savarese ${ }^{7}$ have recently described a potentiation of neuromuscular blockade by simultaneous administration of pancuronium and d-tubocurarine. In their study, the combination provided excellent relaxation with smaller amounts of each drug than would be anticipated if their effects were simply additive. Spontaneous recovery times were not prolonged and in fact were shorter than the spontaneous recovery times from d-tubocurarine alone. While they state that the "neuromuscular blockade in every patient was easily reversible", ? a detailed analysis was not included.

The present study was designed to imitate the most extreme clinical situation: each time an increment was required, the choice of muscle relaxant changed. Thus, patients received alternating doses of d-tubocurarine and pancuronium. Adequate relaxation as determined by the train-of-four method was obtained in all cases, and reversal times with neostigmine were similar to the reversal times for pancuronium alone.

It is concluded that the anaesthetist may alternate between d-tubocurarine and pancuronium according to the patient's requirements, without fear of difficulty in reversing the neuromuscular blockade with neostigmine. As always, monitoring of neuromuscular blockade and recovery is advised.

\section{REFERENCES}

1. Frankel, D.Z.N., Sandham, G. \& Rebuck, A.S. A new method of measuring $\mathrm{PCO}_{2}$ during anaesthesia. Br. J. Anaesthesia 51: 215 (1979).

2. LEE, C.M. Train-of-four quantitation of competitive neuromuscular block. Anesth. Analg. 54: 649 (1975).

3. KATZ, R.L. Clinical neuromuscular pharmacology of pancuronium. Anesthesiology 34: 550 1971.

4. Stiffel, M.D., Hameroff, S.R., BlitT, C.D. \& CoRK, R.C. Variability in assessment of neuromuscular blockade. Anesthesiology 52: 436 (1980).

5. KrIEG, N, CruL, J.F. \& BoolJ, L.H. Relative potency of ORG NC45, pancuronium, alcuronium and tubocurarine in anaesthetized man. $\mathrm{Br}$. J. Anaesthesia 52: 783 (1980).

6. Savarese, J.J., Ali, H.H. \& Antonio, R.P. The clinical pharmacology of metocurine. Anesthesiology 47: 277 (1977).

7. Lebowitz, P.W., Ramsey, F.M., Savarese, J.J. \& ALI, H.A. Potentiation of neuromuscular blockade in man produced by combinations of pancuronium and metocurine or pancuronium and d-tubocurarine. Anesth. Analg. 59: 604 (1980).

\section{RÉSUME}

L'efficacité de la néostigmine à lever le bloc neuro-musculaire produit par les agents non dépolarisants a été étudiée chez 17 patients qui ont reçu en cours d'anesthésie des doses alternantes de d-tubocurarine et de pancuronium. Les temps nécessaires à la levée des blocs étaient semblables à ceux déjà rapportés lorsque le pancuronium était le seul relaxant utilisé. On conclut que l'anesthésiste peut utiliser les deux agents chez un même malade sans perte d'efficacité de la néostigmine pour la levée du bloc. 